\title{
Influence of Microwave Irradiation Method on the Sintering of Barium Titanate with Liquid Phase
}

\author{
Masaki YASUOKA, Takashi SHIRAI, Yutsuki NISHIMURA, Yoshiaki KINEMUCHI and Koji WATARI \\ National Institute of Advanced Industrial Science and Technology (AIST), \\ 2266-98, Anagahora, Shimo-Shidami, Moriyama-ku, Nagoya-shi 463-8560
}

\author{
マイクロ波の照射方法の違いがチタン酸バリウムの液相焼結に及ぼす影響について \\ 安岡正喜·白井 孝·西村ゆつき·杵鞭義明 $\cdot$ 渡利広司 \\ 産業技術総合研究所 先進製造プロセス研究部門，463-8560 名古屋市守山区下志段味穴ケ洞 2266-98
}

\begin{abstract}
The ceramic industry uses enormous amounts of energy to make products at high temperatures. Therefore energy-saving measures based on sintering process improvements are being examined. Barium titanate in the presence of a liquid phase was irradiated by two different methods during microwave sintering: an intermittent use of the same high power levels (time-control method) and a continuous use of lower, increasing levels of power (powercontrol method). As a result, it is concluded that the liquid phase is generated faster in the time-control method provided that the microwave irradiation is carried out at a temperature which is higher than the generation temperature of liquid phase. The liquid phase was generated at a wider temperature in the power-control method. It has been understood that the temperature control becomes difficult, though the time-control method is more efficient for energy efficiency.

[Received November 28, 2005; Accepted March 16, 2006]
\end{abstract}

Key-words : Microwave sintering, Microstructure, Power-control method, Time-control method, Liquid-phase sintering, Barium titanate

\section{Introduction}

To protect the Earth's environment, 21st century manufacturing industries must reduce their consumption of energy. Because the ceramic industry uses sintering processes to make its products, the use of sintering's necessary high temperatures requires large quantities of energy. If this energy could be used more efficiently, less would be consumed. This would result not only in the saving of energy, but also in improvements in the sintering processes. The microwave-sintering process has attracted attention since the $1990 \mathrm{~s}^{1-6)}$ as being energyefficient, and its advantages are threefold: (1) selective heating can be performed; (2) homogeneous heating is achieved; and (3) the temperature can be raised or lowered rapidly. By means of these advantages, this process can be applied to the fabrication of various kinds of products in small quantities.

Barium titanate is a well-known material used in multilayer ceramics and thick-film capacitors because of its high dielectric constant. ${ }^{77}{ }^{8)}$ Since it is used in large quantities as an electronic material, the application of low-temperature sintering would create large energy savings. A low-temperature sintering method was developed ${ }^{9)}$ that combines a microwave method, which is expected to save energy, with a liquid-phase method currently being used as a low-temperature sintering method. ${ }^{10)-14)}$ The component of the liquid phase being used is barium borate, which is known to form a liquid phase at $942^{\circ} \mathrm{C}$ when mixed with barium titanate, ${ }^{15)}$ but it forms no other chemical components.

When samples are heated with power from an electric or microwave furnace, two kinds of methods can be used to control the temperature: (1) intermittent powering of the magnetron at a fixed high-power output (time-control method); or (2) continuous powering of the magnetron with a variable power output (power-control method). Because the microwave-sintering process uses self-generated heat from the sample when it absorbs the microwaves, it is believed that the heat- ing state of the sample can be influenced by the microwaveirradiation method. Moreover, differences in the pattern of energy absorption by the sample arise when the sample is direct-heated by different irradiation methods; thus differences in energy efficiency could result.

We irradiated a sample by using two kinds of irradiation methods during microwave sintering: a high amount of electric power applied intermittently and a lower amount of power applied continuously. We report here the energy efficiency produced by these two different methods.

\section{Experimental}

Barium titanate (BT-01, Sakai Chemical Industry Co.) was used as raw material. Barium borate was chosen as liquid phase. Barium carbonate $(99.9 \%$, Wako Pure Chemical Industries Co.) and boric acid (99.5\% [minimum], Kanto Chemical Co.) were used to prepare the sample. The amount of liquid phase was added $1.5 \mathrm{~mol} \%$. The barium carbonate and boric acid were directly mixed with barium titanate, and green pellets with a diameter of $18 \mathrm{~mm}$ were formed by use of a uniaxial pressure of $17 \mathrm{MPa}$ and a cold isostatic pressure of $98 \mathrm{MPa}$. A magnetron multimode microwave furnace (MWMaster, Mino Ceramic Co., Ltd., Mizunami) was used for the sintering experiments at $2.45 \mathrm{GHz}$. Figure 1 is a schematic illustration of the system. The sample was placed into a thermally insulated box, to the inner surface of which $\mathrm{SiC}$ had been applied. The $\mathrm{SiC}$ acts as a susceptor. The generation source of the microwaves was a magnetron with a $1.5 \mathrm{~kW}$ maximum rating at $2.45 \mathrm{GHz}$. With the power-control method, the temperature was controlled by adjusting the voltage and current to induce a variable load on the magnetron. With the time-control method, the temperature was controlled by adjusting the oscillation time of the magnetron, to which a maximum load was applied. The sample temperature was measured with an optical radiation thermometer. The 


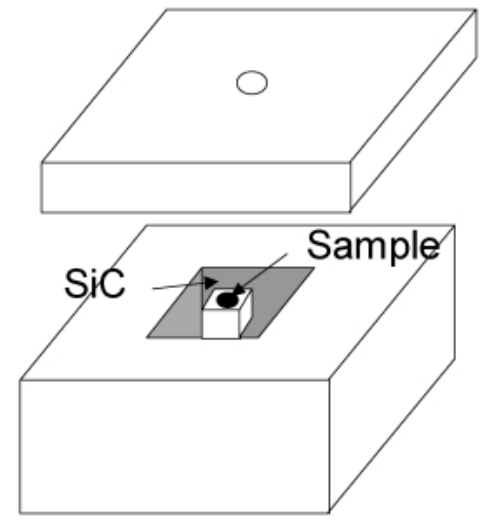

Fig. 1. Illustration of sample setting for microwave sintering.

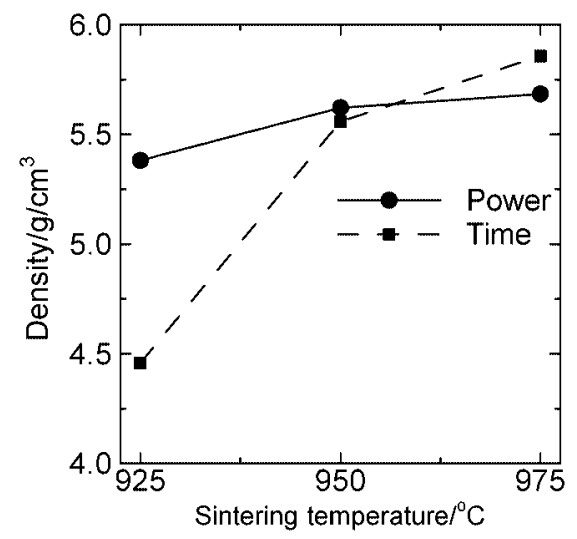

Fig. 2. Relation between sintering temperature and density.

heating rate was $30^{\circ} \mathrm{C} \cdot \mathrm{min}^{-1}$; the holding time was $20 \mathrm{~min}$. Sintering temperature was controlled by a proportional integral differential (PID) controller based on the temperature read with an infrared radiation thermometer. Density was measured by the Archimedes method.

\section{Results and discussion}

Figure 2 shows the relationship between sintering temperature and density. The sample was not densified at $925^{\circ} \mathrm{C}$, but it was densified above $950^{\circ} \mathrm{C}$ during the time-control method. On the other hand, the density indicates a high value in the power-control method with $5.4 \mathrm{~g} \cdot \mathrm{cm}^{-3}$ at even $925^{\circ} \mathrm{C}$, and it was also densified above $950^{\circ} \mathrm{C}$. In the time-control method, the sample's densification occurred rapidly with increasing temperature. In the power-control method, however, the densification progressed only slowly with increasing temperature.

Changes in the power output from the magnetron and the effective electric power during heating are shown in Figs. 3-5. Figures 3, 4, and 5 show the change of temperature and power output at $925^{\circ} \mathrm{C}, 950^{\circ} \mathrm{C}$, and $975^{\circ} \mathrm{C}$, respectively. When the time-control method was used, the temperature change was extreme in any sintering temperature. The electric power output is the measured amount of electric power emitted from the magnetron, and the effective electric power is the value achieved by subtracting the amount of reflected electric power from the electric power output. The amount of reflected electric power is the amount of electric power that returns to the magnetron without being consumed by the microwave furnace. With the time-control method, on-off control was per-

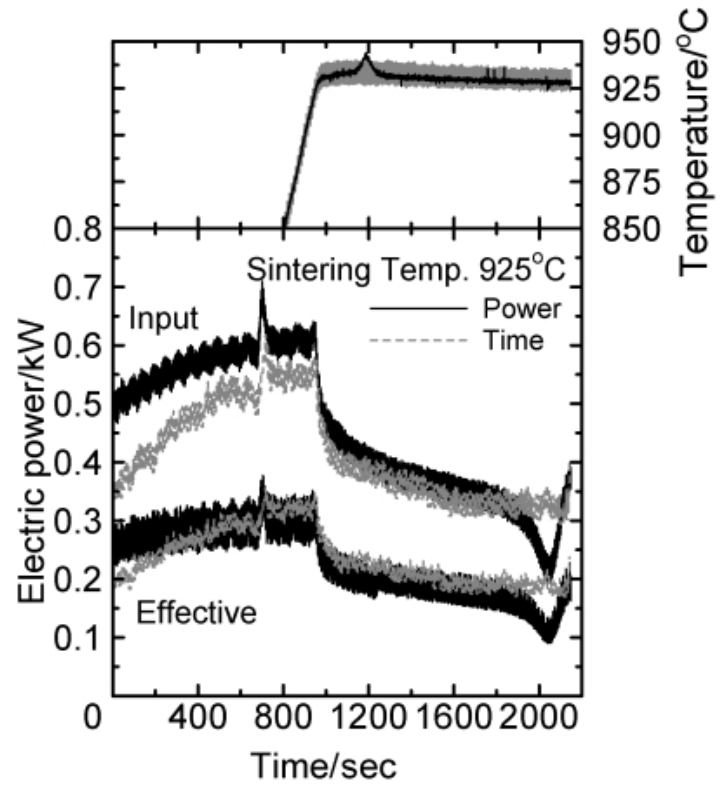

Fig. 3. Relation between time and electric power sintered at $925^{\circ} \mathrm{C}$.

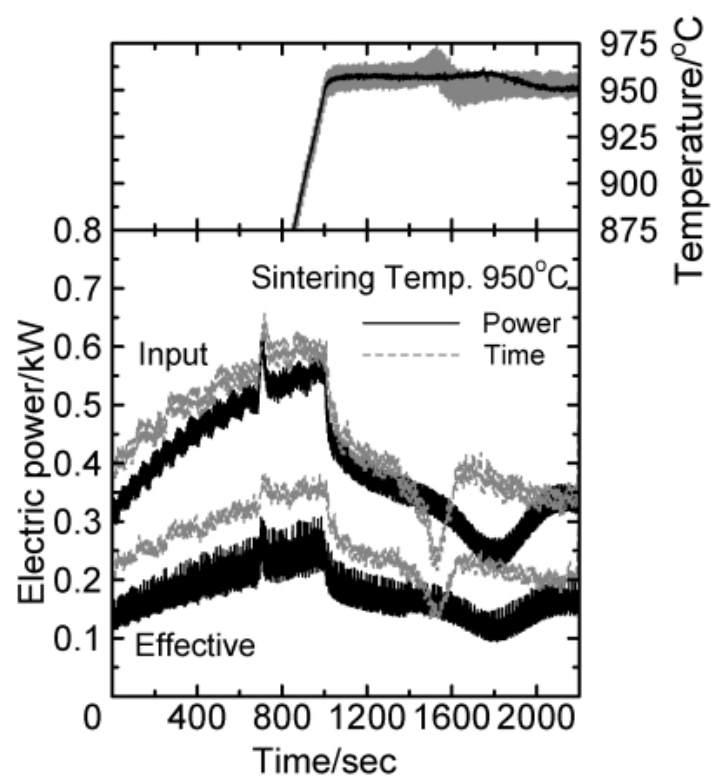

Fig. 4. Relation between time and electric power sintered at $950^{\circ} \mathrm{C}$.

formed every $10 \mathrm{~s}$ as 1 cycle to protect the magnetron. The average amount of power applied for $10 \mathrm{~s}$ on both sides of the time concerned was used to calculate the amount of electric power at a certain time. The amount of electric power output from the magnetron increased with temperature in both control methods. When the specimen reached a fixed temperature, the power output value decreased gently.

We make a comparison from Fig. 3 to Fig. 5. After it had entered the state of temperature maintenance, a rapid decrease in the output was observed, except in the setting of sintered at $925^{\circ} \mathrm{C}$ in the time-control method. The change in output is closely related to the temperature change measured with the radiation thermometer. Because the temperature is measured with an infrared thermometer, the variations in both the temperature and the change in the emissivity of the sample are 


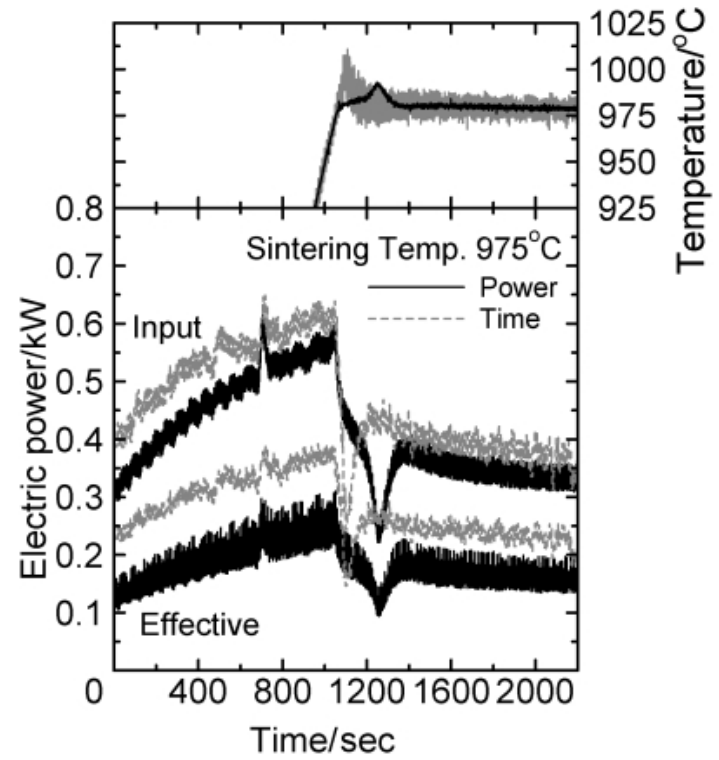

Fig. 5. Relation between time and electric power sintered at $975^{\circ} \mathrm{C}$.

thought to be a cause of the change in output. Such a change was not observed while the temperature was maintained when the barium titanate without the liquid phase was sintered. Because the liquid phase is used in this experiment, it is thus considered to be the reason for the change in output. In brief, it is believed that the change of the sample's emissivity by generating the liquid phase caused the change of output power, especially in consideration of the relation to the decreased peak of the output and the sintering temperature. When the sample was sintered at $950^{\circ} \mathrm{C}$ and $975^{\circ} \mathrm{C}$, this peak was observed earlier with the time-control method than with the power-control method. When the sintering temperature is higher than the liquid phase generation temperature, the sample was accelerated to be densified with the time-control method. However, this peak was not observed when the time-control method was used at $925^{\circ} \mathrm{C}$. When the sintering temperature is lower than the liquid-phase generation temperature, the sample is blocked from becoming densified with the time-control method. On the contrary, however, the sample using the power-control method is densified at any sintering temperature. This explains the difference. If the sintering temperature were higher than that required for the liquid-phase generation, the liquid phase was generated without difficulty, followed by the densification of the sample. But when it is lower, the circumstances are different. When it does not reach the liquid-phase generation temperature, it is thought that the generation of the liquid phase is difficult. However, the temperature measured at this time is an average temperature of the sample. There is a possibility that the temperature of part of the sample is high because the amount of absorption of the microwave's energy will be different depending on the material. The microwave is intermittently irradiated to the sample for the time-control method. Therefore the sample alternates between hot and cool. It is thought that the liquid phase cannot exist in a steady state because the temperature change is large. In the time-con- trol method, the liquid-phase sintering does not advance, and the sample is not densified. In the power-control method, however, it is thought that the liquid phase is able to exist in a steady state because the sample was irradiated in the energy of the microwave, and the temperature change was small.

Energy efficiency is defined as the ratio of the effective power to the input power. These values of each sintering condition were compared. Under any sintering conditions, the values of energy efficiency were about 0.5 and 0.6 for the power-control method and the time-control method, respectively. The energy efficiency was good on using the time-control method. However, the time-control method has a problematic point because the range of the temperature that was able to be sintered was very narrow. It has been understood that the range of sintering temperature is restricted when we prioritize efficiency.

\section{Conclusions}

We obtained the following results when barium titanate with liquid phase was sintered by two different microwave irradiation methods. As the temperature increased in the neighborhood of the liquid-phase generation temperature, the sample was densified progressively in the power-control method. On the contrary, the density of the sample in the time-control method changed greatly on the boundary of the liquid-phase generation temperature. It is thought that this difference depends on the difference in the method supplying the energy of the microwave.

\section{References}

1) Sutton, W. H., Am. Ceram. Soc. Bull., Vol. 68, pp. 376-386 (1989).

2) Katz, J. D., Annual Review of Materials, Vol. 22, pp. 153-170 (1992).

3) Saltiel, C., Fathi, Z. and Sutton, W. H., Mechanical Engineering, Vol. 117, pp. 102-105 (1995).

4) Clark, D. E. and Sutton, W. H., Annual Review of Materials, Vol. 26, pp. 299-331 (1996).

5) Ayappa, K. G., Reviews in Chemical Engineering, Vol. 13, pp. 1-69 (1997).

6) Lee, W. C., Liu, K. S., Wu, M. W. and Lin, I. N., Ferroelectrics, Vol. 231, pp. 825-830 (1999).

7) Sakabe, Y., MRS International Meeting Advanced Material, Vol. 10, pp. 119-129 (1989).

8) Goodman, G., "Ceramic Capacitor Materials," in Ceramic Materials for Electronics, Ed. Buchanan, R. C., Marcel Dekker, New York (1986) pp. 79-138.

9) Yasuoka, M., Nishimura, Y., Nagaoka, T. and Watari, K., Adv. in Tech. of Mat. and Mat. Proc. J., Vol. 6, pp. 270-275 (2004).

10) Chowdary, K. R. and Subbarao, E. C., Ferroelectrics, Vol. 37, pp. 689-692 (1981).

11) Burn, L., Journal of Material Science, Vol. 17, pp. 1398-1408 (1982).

12) Ho, I. C., J. Am. Ceram. Soc., Vol. 77, pp. 829-832 (1994).

13) Kolar, D., Trintelj, M. and Marsel, L., Journal de Physique, Vol. 47, pp. C1-447-450 (1986).

14) Lee, J. H., Kim, J. J., Wang, H. and Cho, S. H., Journal of Material Research, Vol. 7, pp. 1600-1604 (2000).

15) Goto, Y. and Cross, L. E., J. Ceram. Soc. Japan (YogyoKyokai-Shi), Vol. 77, pp. 355-357 (1969). 